\title{
Aripiprazole is effective for relapse prevention in people with chronic stable schizophrenia
}

Pigott TA, Carson WH, Saha AR, et al. Aripiprazole for the prevention of relapse in stabilized patients with chronic schizophrenia: a placebo-controlled 26-week study. J Clin Psychiatry 2003;64:1048-56.

Does maintenance aripiprazole prevent relapse in people with chronic schizophrenia with residual symptomatology?

\section{METHODS}

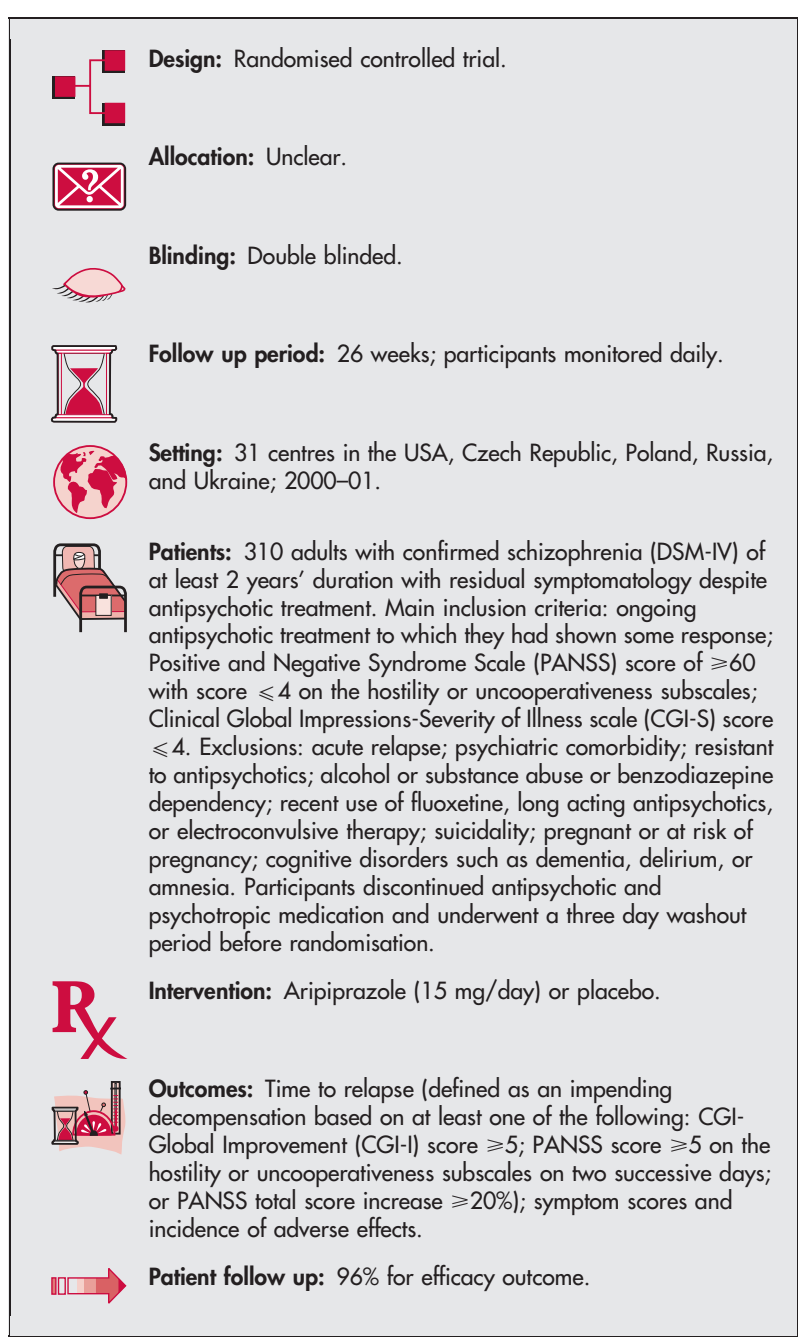

\section{MAIN RESULTS}

Aripiprazole significantly decreased relapse rate compared with placebo (Kaplan-Meier survival rates at week 26: 62.6\% with aripiprazole $v 39.4 \%$ with placebo; $\mathrm{p}<0.001$; RR for relapse 0.50 , $95 \%$ CI 0.35 to 0.71 ). Aripiprazole significantly improved schizophrenic symptoms compared with placebo at 26 weeks (PANSS total score, CGI-S and CGI-I scales; see table). Both groups had a similar

For correspondence: Dr T Pigott, Department of Psychiatry, University of Florida, UF Brain Institute, Gainesville, Florida, USA; tpigott@psych.med. ufl.edu

Sources of funding: Bristol-Myers Squibb, Princeton, and Otsuka Pharmaceutical Co Ltd, Tokyo, Japan.

\section{Commentary}

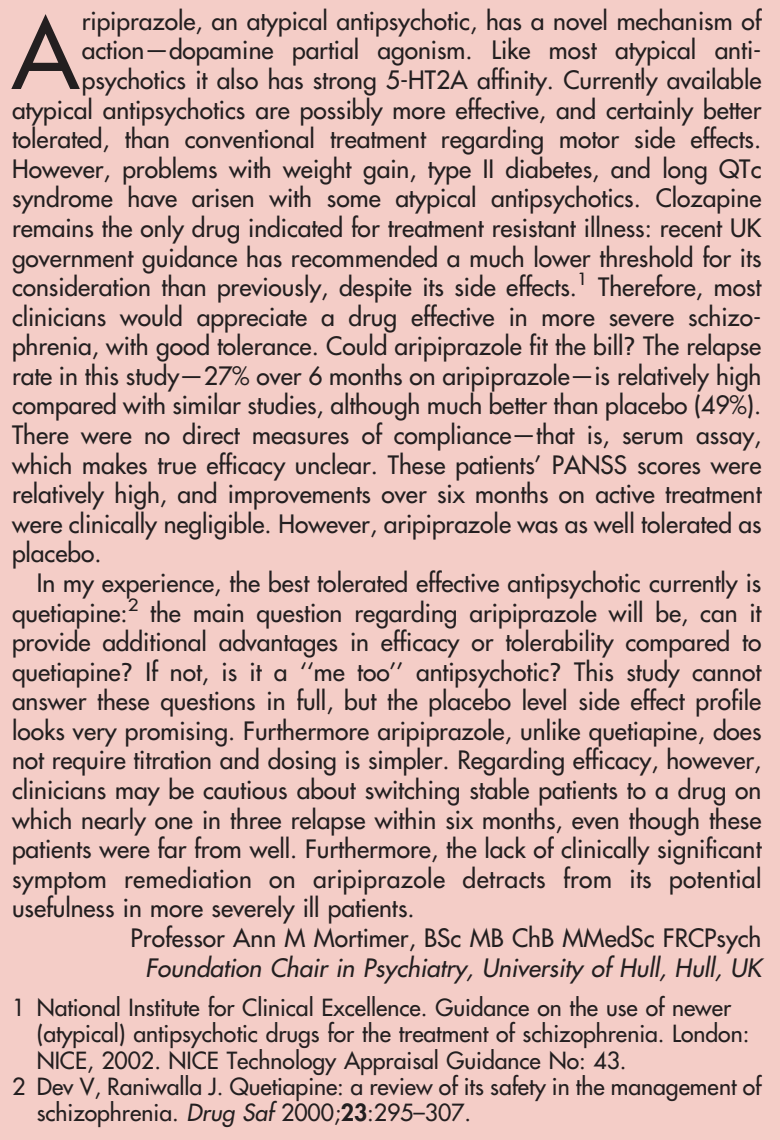

incidence of adverse effects $(79.7 \%$ with aripiprazole $v 77.1 \%$ with placebo).

\section{CONCLUSIONS}

Aripirazole is effective for preventing relapse in people with chronic schizophrenia and residual symptomatology over a six month period.

Table Mean change in PANSS and CGI scores from baseline to week 26

\begin{tabular}{llll}
\hline & Aripiprazole & Placebo & p Value \\
\hline PANSS total & -2.08 & +4.50 & $\leqslant 0.01$ \\
PANSS positive subscale & +0.12 & +2.37 & $\leqslant 0.01$ \\
PANSS negative subscale & -1.40 & -0.54 & NS \\
PANSS derived BPRS & -0.21 & +1.17 & $\leqslant 0.01$ \\
CGI-S & +0.15 & +0.40 & $\leqslant 0.05$ \\
CGI-I & +3.74 & +4.47 & $\leqslant 0.01$ \\
\hline
\end{tabular}

BPRS, brief psychiatric rating scale; NS, not significant. 